\title{
AVALIAÇÃO DO PROGRAMA DE SUGESTÕES DE MELHORIAS DE UMA FÁBRICA DE ALIMENTOS NA REGIÃO METROPOLITANA DO RECIFE A PARTIR DAS IDEIAS SUBMETIDAS PELOS OPERADORES
}

Camila Corrêa (UFPE) camilacorreamelo@gmail.com

\section{Resumo}

Os programas de sugestões de melhorias adotados pelas organizações contribuem para o progresso das condições de trabalho e da forma como as atividades são realizadas pelos associados e promovem o maior empoderamento dos envolvidos. Este trabalho é um estudo de caso aplicado a uma fábrica de alimentos na Região Metropolitana do Recife para avaliar o desempenho do programa de sugestões propostas pelos associados. O trabalho foi baseado nos dados disponibilizados pela organização. O estudo de caso foi construído sob a discussão de quatro pontos: conceito de kaizen, estágio do programa de melhoria, definição dos 7 desperdícios e a clareza na descrição dos problemas e as propostas. Baseados nas investigações, foram identificadas oportunidades de treinamento e educação para a filosofia de kaizen e maior envolvimento e aproximação da liderança com a operação para a condução do programa de melhoria contínua na organização.

Palavras-Chaves: Programa de sugestões, Kaizen, Melhoria Contínua, Lean, 7 Perdas da Produção

\section{Introdução}

De acordo com Liker (2005) a excelência operacional tem sido uma arma estratégica. Diante de ambiente cada vez mais competitivo, aquelas organizações que trabalham diariamente para a melhoria contínua de suas operações conseguem sair a frente. A ferramenta de kaizen, por exemplo, tem se mostrado como um instrumento que ajuda às organizações a desenvolverem operações de maior valor agregado (LIKER, 2005), colaborando para com o sucesso competitivo delas.

O kaizen é uma ferramenta que dispensa a intervenção da liderança para que as melhorias operacionais sejam realizadas; na verdade, ele estimula a criatividade das pessoas envolvidas nos processos e as empodera a realizar um trabalho de forma mais eficiente e eficaz (OSTERLING E MARTIN, 2007). Dessa forma, considera-se o objetivo do kaizen como o de humanizar o ambiente de trabalho, eliminando aquelas atividades que não agregam valor, 
além de ensinar os operadores a resolver os problemas de forma eficiente (OSTERLING E MARTIN, 2007), desenvolvendo as pessoas para analisar os seus métodos de trabalho e realizar melhorias (KATO E SMALLEY, 2011).

Diante da contribuição da ferramenta de kaizen para com o sucesso competitivo de uma organização, este trabalho avalia a qualidade das sugestões de melhorias apresentadas pelos operadores em uma indústria de alimentos na Região Metropolitana do Recife. As melhorias poderiam ser relacionadas às áreas de qualidade, segurança e desperdício. No entanto, para este trabalho, foram consideradas apenas as ideias associadas à área desperdício, ou seja, aquelas que buscavam eliminar uma das 7 perdas operacionais do processo - transporte, espera, superprodução, estoque, movimentação, defeito e processamento - a fim de tornar o trabalho dos operadores simples e enxuto.

A partir das propostas coletadas no banco de dados da organização, primeiro buscou-se compreender o entendimento pela operação sobre o conceito de kaizen (melhorias simples versus inovação); segundo analisou-se a clareza da descrição do problema levantado pelo operador e sua respectiva classificação em relação às sete perdas; e, por último, observou a maneira com que as ideias eram apresentadas, seja por meio de desenho ou foto, e seu detalhamento quanto ao real ganho para a operação e os materiais necessários para que a realização da melhoria fosse possível, isto é importante pois ajuda no processo de aprovação da melhoria e a sua consequente implementação.

A temática do kaizen já foi abordada em outros estudos. Gołaś et al (2016) apresentam um estudo de caso em uma fábrica de baterias e Mazzocato et al (2016) avaliaram a ferramenta de melhoria contínua no setor hospitalar. Moica, Veres e Marian (2018) evidenciam quais os efeitos de um programa de sugestões nos indicadores de produção da organização. Os outros trabalhos apresentam as propostas de melhorias dos funcionários relacionadas a realização de evento de kaizen como no estudo de Alagic (2020) em uma fábrica de processamento de madeira, em Vol et al (2019) em uma indústria de embalagens e em Oliveros, Granja e Dionisio (2018) no setor de construção civil. Assim, constata-se a multiplicidade de aplicações da ferramenta kaizen.

O trabalho está organizado em sete partes: nesta primeira seção apresenta a temática deste trabalho - kaizen; a segunda parte aborda a metodologia adotada; na terceira parte traz o referencial teórico do conceito de kaizen teian. Na seção quatro apresenta a situação atual do programa de sugestões de melhorias na organização do estudo de caso. Na quinta seção são realizadas discussões a respeito do programa de sugestões a partir da análise das ideias 
propostas nos formulários submetidos pelos associados. As limitações foram expostas na seção 6. E, por último, conclui-se a discussão com propostas de melhorias para o programa.

\section{Metodologia}

Esta pesquisa é classificada quanto aos objetivos, de acordo com GIL (2002), como pesquisa descritiva, haja vista que o objetivo deste trabalho é descrever e investigar as características do programa de sugestões implementado na organização. Em relação a abordagem da pesquisa, considera-se como uma pesquisa qualitativa, pois os dados avaliados, advindos dos formulários de sugestões, são baseados nas perspectivas pessoais dos operadores, valendo-se de descrições particulares sobre um problema ou uma situação, além de fotos e desenhos (OLIVEIRA, 2011).

Quanto a natureza deste trabalho, trata-se de uma pesquisa aplicada por buscar "gerar conhecimento para aplicação prática" (GERHARDT E SILVEIRA, 2009. p. 35) em uma fábrica de alimentos na Região Metropolitana do Recife. Além disso, valeu-se de pesquisa documental e estudo de caso como procedimentos para o seu desenvolvimento.

Os dados usados para este estudo foram coletados da organização. Os formulários de sugestões eram depositados em um quadro, os quais eram coletados diariamente, registrados em uma planilha com as informações de pessoas envolvidas com a melhoria, área onde o problema foi observado, descrição do problema, a necessidade da compra de material para a implementação e o fator custo versus benefício, e em seguida escaneados para arquivamento eletrônico. Os formulários foram avaliados a fim de caracterizar o programa de melhoria vigente na organização e identificar as possibilidades de melhorias para a sua restruturação de forma a garantir robustez e resultados sustentáveis.

\section{Kaizen Teian}

Segundo Oakland (1994), o kaizen teian é um sistema de propostas de pequenas melhorias no ambiente de trabalho dos operadores que não requer altos esforços e custos para serem implementados. A distinção mais relevante desse programa em relação aos demais programas de melhoria é que as recompensas oferecidas são pequenas e o prazo de implementação é muito curto e a soma de todas as pequenas sugestões propostas somam substanciais melhoramentos e economias. O sistema de kaizen teian é simples, mas eficiente, capaz de 
motivar todos os operadores a gerar e oferecer novas ideias de melhorias de forma contínua, de tal forma que sejam capazes de identificar os problemas e participem do processo de formulação de solução para os problemas (TOZANA \& BODEK, 2001).

O objetivo do kaizen teian é que os operadores sejam capazes de propor e implementar o máximo de ideias que conseguir (OAKLAND, 1994). Dessa forma, para Tozawa e Bodek (2001) o foco não está na sugestão de ideias para que outra pessoa a implemente, mas sim existe o foco da implementação pelo próprio operador realize a sua ideia, isso motivar os operários a tornar seu local de trabalho mais fácil e organização e tomar iniciativa para realizar pequenas mudanças que possam ajudar na redução dos custos, melhorar a qualidade e segurança, reduzir o tempo de entrega dos produtos e serviços e logo reduzir os preços de seus produtos para se manterem competitiva com uma maior fatia de participação no mercado.

Ainda segundo Tozawa e Bodek (2001), o kaizen teian é a forma mais fácil e efetiva para inspirar o pensamento de melhoria contínua nos operadores e encorajá-los a experienciar a satisfação ou alegria de ver como uma nova ideia que resolve um problema, implementar uma solução e escrever uma ideia para mostrar e dividir com os outros colegas de trabalho. Encorajar os operadores a implementar suas ideias de melhoria diferencia do sistema tradicional de sugestões e essa nova proposta de melhorias pelos operadores é um importante sistema que ajuda todos os operadores a reconhecer seu potencial criativo e se tornar mais envolvido no processo de melhoria dentro da organização (TOZAWA E BODEK, 2001).

Para JAHR (1996) o sistema de proposta considera que as melhorias devem ocorrer na área de trabalho e estarem relacionadas com o trabalho do operador, as propostas que tem o objetivo de melhorar o trabalho, muito mais do que propor ideias abstratas, devem ser realizadas e essas melhorias devem ser eficazes, mas além disso, elas devem ser vistas como uma forma de motivar as pessoas e desenvolver sua capacidade criativa. Na tabela 1 estão descritos os pontos fortes e fracos sobre o kaizen teian propostos Belliveau et al (2007).

Tabela 1 - Pontos fortes e fracos do Kaizen Teian

\begin{tabular}{|c|c|}
\hline Pontos fortes & Pontos fracos \\
\hline $\begin{array}{l}\text { Ideias incrementais são mais fáceis de } \\
\text { implementar e promovem um } \\
\text { melhoramento contínuo }\end{array}$ & $\begin{array}{l}\text { Separação de pequenas ideias que poderiam } \\
\text { ser combinadas, o programa pode ter uso } \\
\text { indevido }\end{array}$ \\
\hline Adequada para ações rápidas & Pessoa que sugere a melhoria pode ser \\
\hline
\end{tabular}




\begin{tabular}{|l|l|}
\hline & incapaz de realizar a melhoria \\
\hline $\begin{array}{l}\text { Gestão pode ser descentralizada, mas } \\
\text { próximo de quem propõe a ideia }\end{array}$ & \\
\hline $\begin{array}{l}\text { Impulsiona a participação dos operadores } \\
\text { e o programa é avaliado pelo número de } \\
\text { participações }\end{array}$ & \\
\hline
\end{tabular}

Fonte: Adaptado de Belliveau et al (2007)

\section{Situação atual do sistema de sugestões na organização do estudo de caso}

Apesar da ferramenta do kaizen acompanhar as origens da estruturação da filosofia Lean na fábrica de alimentos e todos os associados compreenderem a importância da ferramenta para a organização, verificou que os resultados atuais não são positivos e pouco sustentáveis. Além disso, o programa de kaizen encontra-se em descrédito pelos associados.

O gráfico 1 abaixo ilustra o progresso da participação dos associados no programa em um período de cinco anos. Observa-se que a partir de 2015, as pessoas começaram a ser treinadas para o programa, quando foi estabelecido formalmente pela fábrica. Com acompanhamento e reconhecimento das sugestões de melhoria dos associados e teve, no seu primeiro ano, uma participação de $52 \%$ do total de associados.

Gráfico 1- Participação anual dos associados

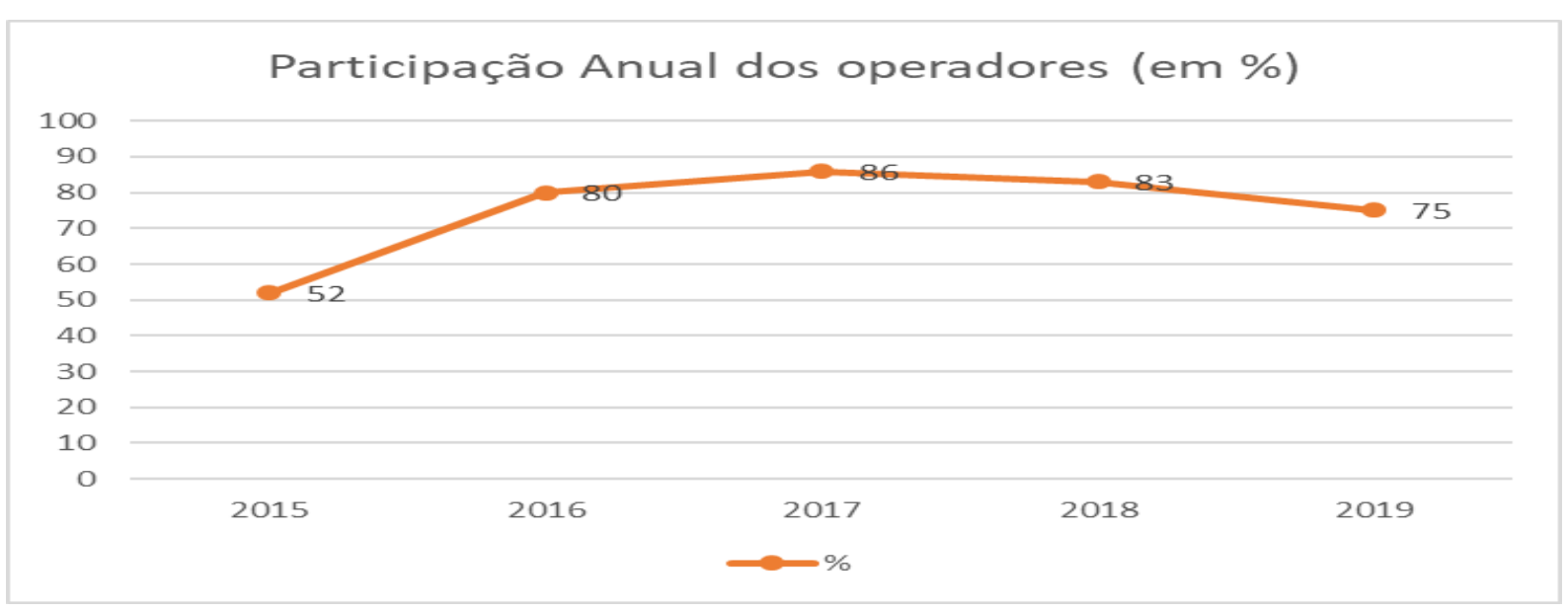

Fonte: Dados da organização (2019)

Durante os dois anos subsequentes 2016 e 2017 a porcentagem de pessoas participantes aumentou, mas dentre os anos de 2018 e 2019 houve uma queda na participação dos 
operadores. O programa de kaizen é uma mudança cultural, dessa forma é preciso motivar os associados regularmente e relembrá-lo da importância do seu papel como agente de melhoria contínua para a organização.

Também se observou uma situação difícil a respeito do histórico das melhorias. A partir do gráfico 2, percebe-se que o número de kaizen sugeridos cresce a cada ano e que apenas no último ano (2019) apresentou uma pequena queda. Por outro lado, quando se estratifica esse número, é possível observar que o número de sugestões dos operadores reprovados aumentou de um ano para outro, exceto de 2018 para 2019, refletido um descompasso quanto ao entendimento sobre os conceitos de kaizen; enquanto o número de kaizens em andamento aumentou consideravelmente todos os anos, de maneira que a proporção do número de kaizens implementados não acompanha o aumento do número de sugestões, por exemplo, uma vez que dos 287 de 2017, 497 de 2018 e 373 de 2019 kaizens abertos, 109, 183 e 207, respectivamente, continuam em andamento em 2020.

Gráfico 2 - Histórico anual de Kaizens

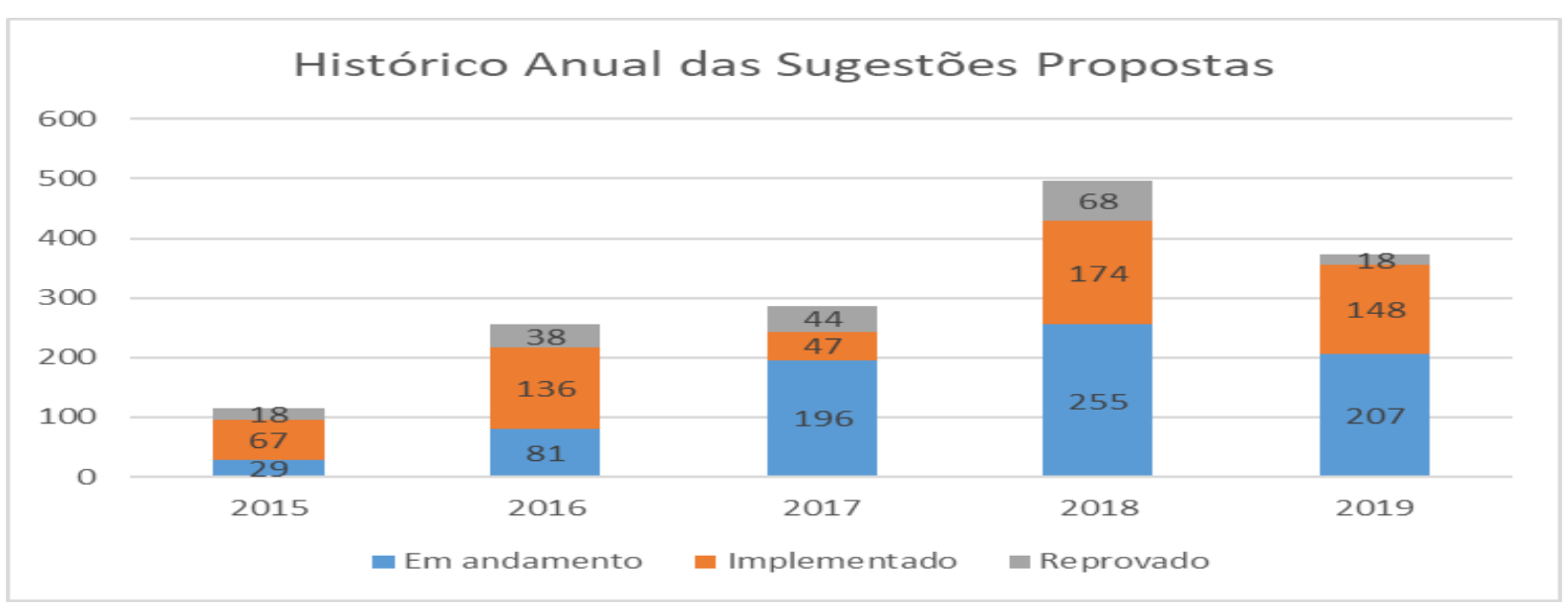

Fonte: Dados da organização (2019)

\section{Kaizen Teian na organização - estudo de caso}

O programa de Kaizen Teian, ou sugestões de melhoria propostas pelos operadores, será avaliado sob quatro perspectivas: conceito de kaizen versus inovação, estágio do programa de melhoria, associação aos 7 desperdícios e clareza na identificação do problema e respectiva descrição da proposta de melhoria. A seguir estão apresentadas algumas discussões para cada uma destas frentes. 


\subsection{Conceito de kaizen versus inovação}

O conceito de kaizen de acordo com JRHA (1992) está associado a melhorias "pequenas, simples e incrementais", em contraste com os sistemas de sugestões tradicionais que significavam rupturas ao processo a partir de grandes mudanças.

A partir desta definição, foram levantados alguns exemplos de sugestões a fim de validar o entendimento da operação em relação proposta fundamental do programa de sugestões da organização.

O kaizen 1 (figura 1) sugere a troca de paleteiras manuais por automáticas. Apesar da sugestão representar uma melhoria às atividades da operação, ela representa uma ruptura das condições atuais, além de requerer um alto investimento e um maior tempo para a sua implantação. A proposta diverge da ideia fundamental do kaizen de ser algo rápido de ser implementado, o qual o próprio associado consegue realizar com os materiais e pessoas que têm à disposição dele (JRHA 1992). Também, essa sugestão vai de encontro com a sétima característica levantada por Martin \& Osterling (2007) que afirma que a criatividade deve vim antes dos investimentos, de modo que os kaizen são melhorias de baixo custo, simples e rápidas.

Figura 1 - Kaizen 1: Exemplo de ideias fáceis e simples de implementação sem investimento

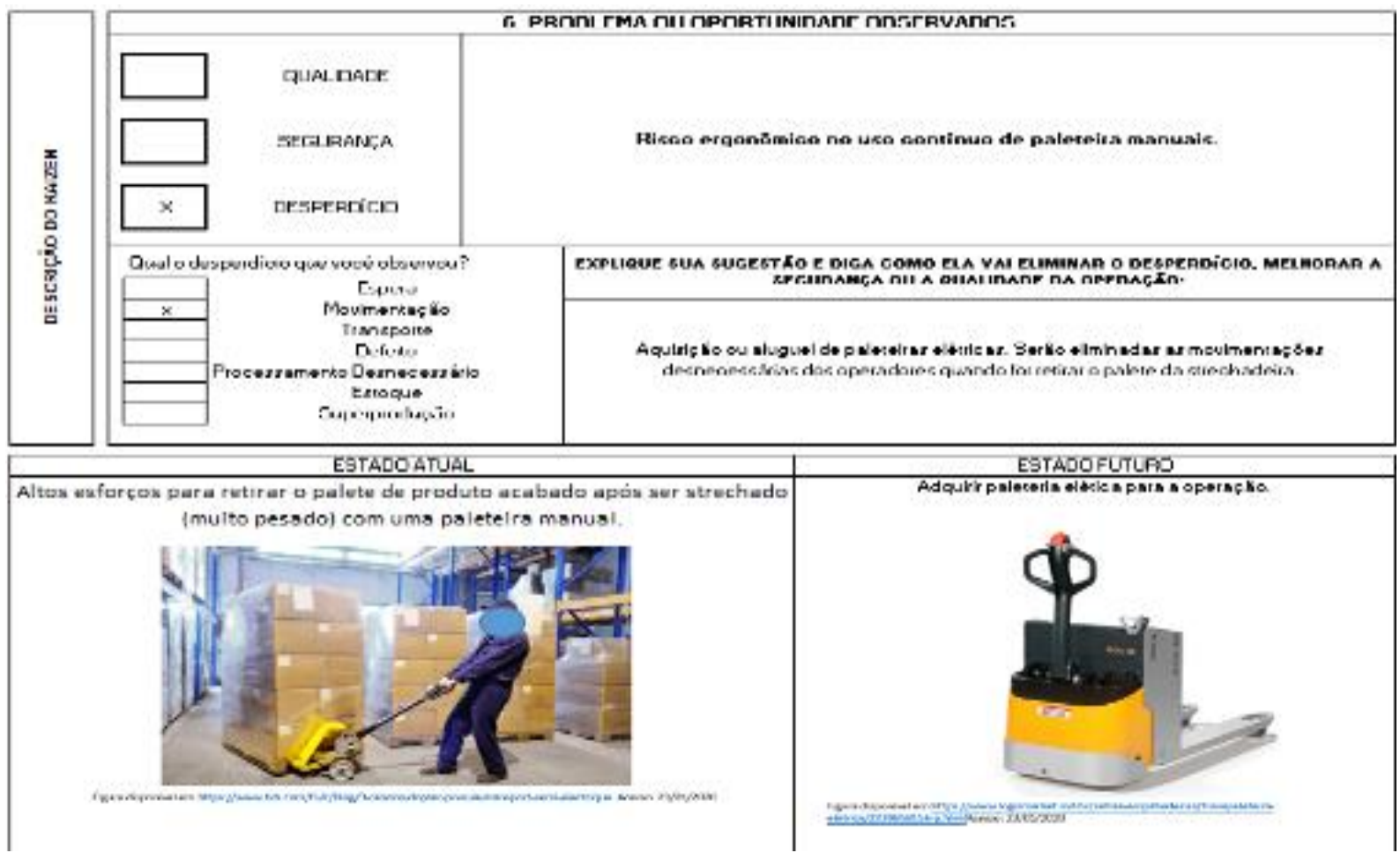

Fonte: Dados da organização (2019) 
Em contraste à proposta anterior, os kaizens a seguir retomam a ideia de propostas simples: sem investimento (figura 2) ou de baixo investimento (figura 3) e rápida e facilmente implementadas pela operação (figura 4).

Figura 2 - Exemplo de ideias fáceis e simples de implementação sem investimento

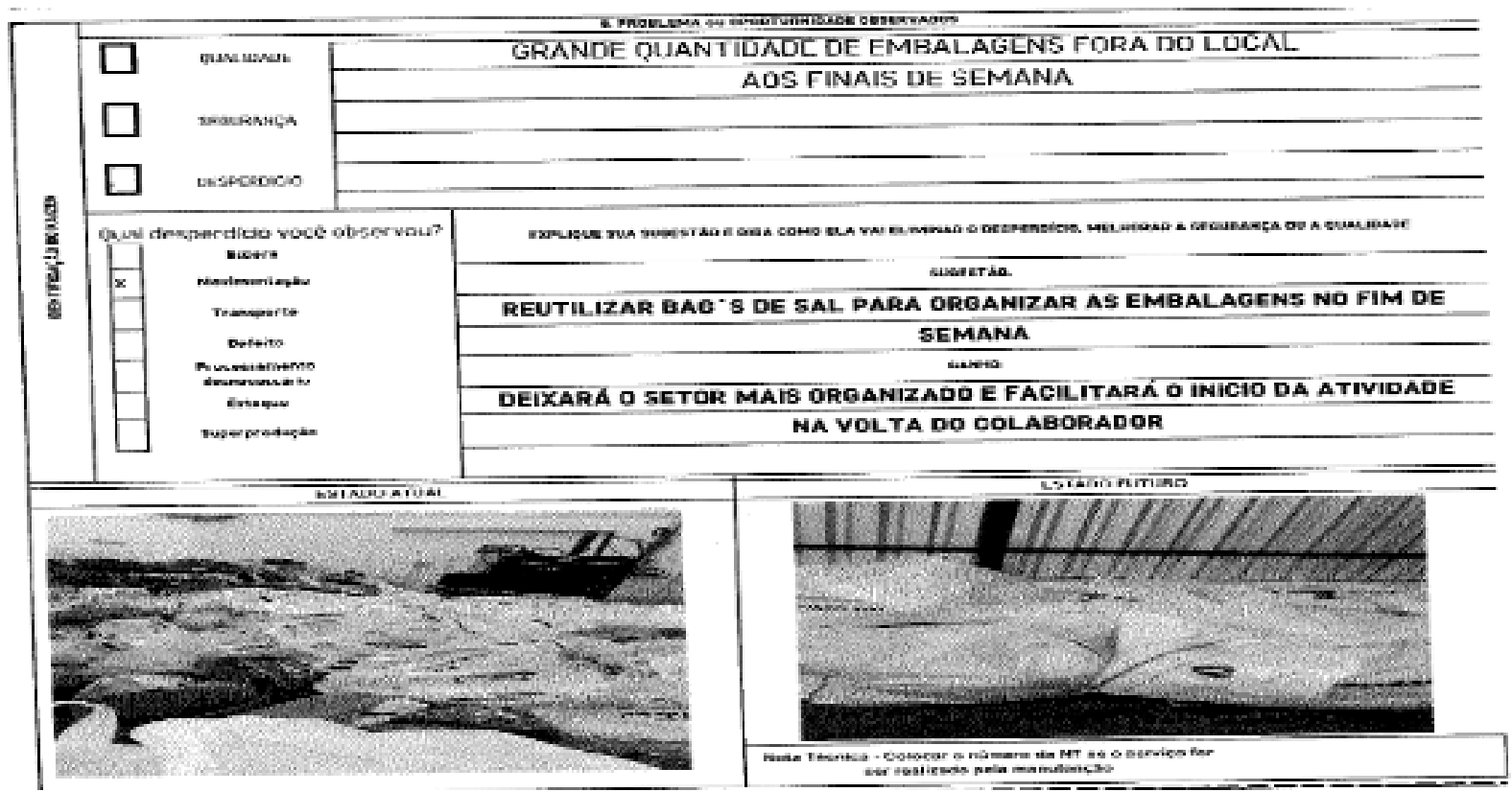

Fonte: Dados da organização (2019)

Figura 3 - Exemplo de ideias simples de implementação com baixo investimento

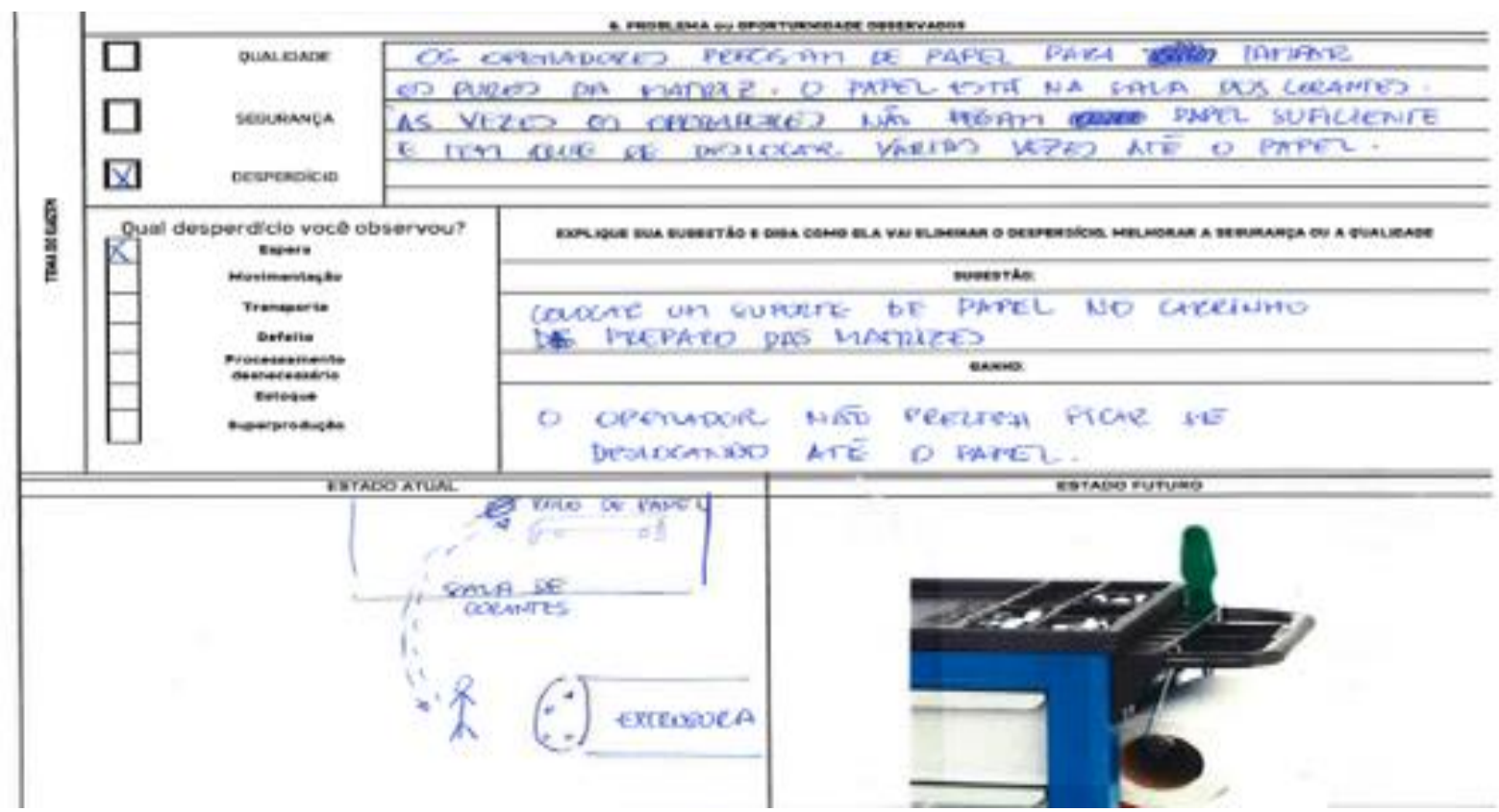

Fonte: Dados da organização (2019) 
Figura 4 - Exemplo de Ideias Fáceis e Simples a ser implementada pelo operador

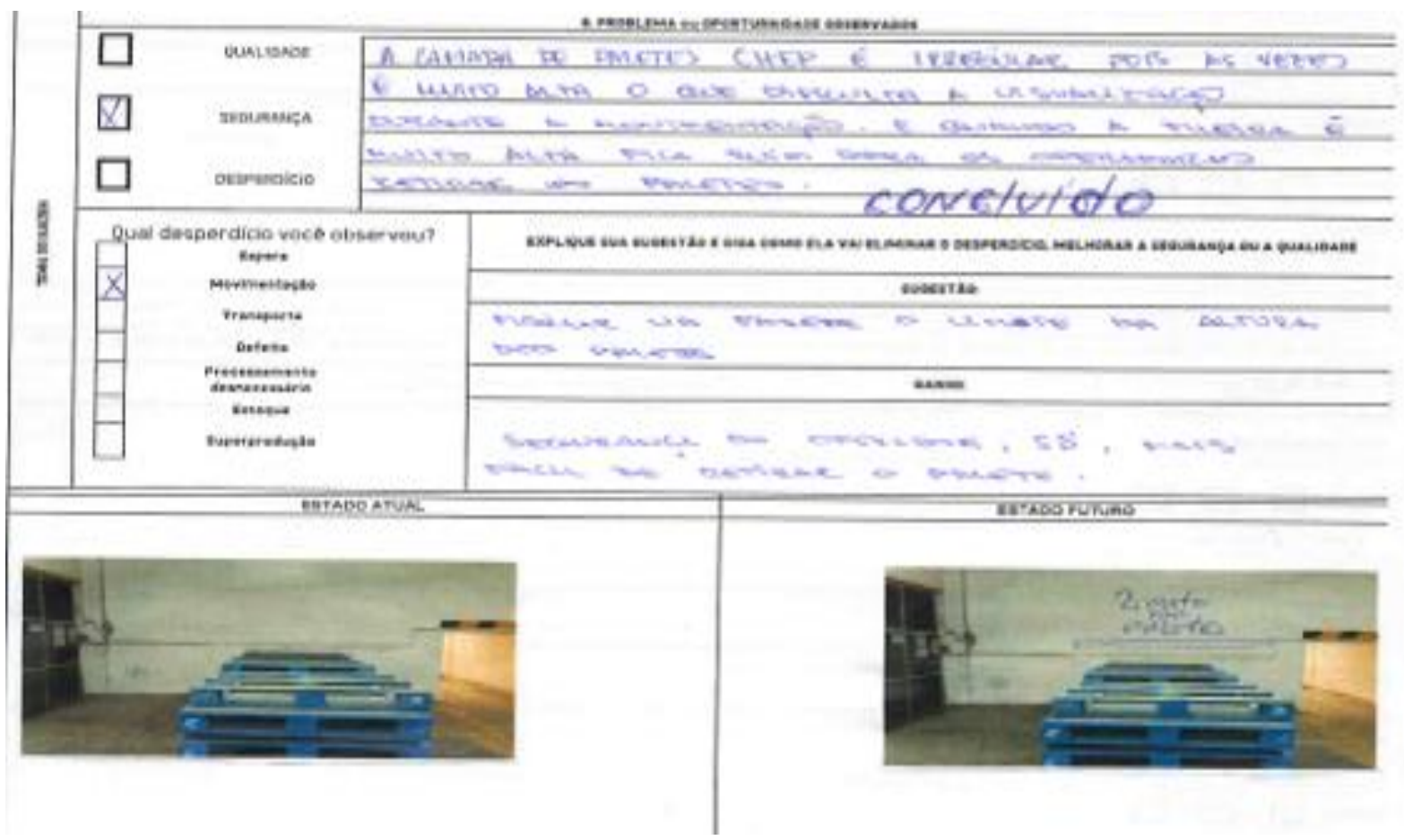

Fonte: Dados da organização (2019)

Baseado nos documentos levantados, observou-se que a maioria dos associados sabe discernir o conceito de kaizen e inovação, no entanto acredita-se ser de fundamental importância a promoção da contínua educação a fim de esclarecer algumas confusões que ainda possam surgir. Além disso, sugere-se criar um documento com situações que ilustrem propostas de kaizen versus inovação, assim, em casos de dúvidas o operador pode recorrer a ele para se certificar em que parte do espectro "kaizen - inovação" a sugestão se encontra.

\subsection{Estágio do programa de sugestões}

Para Imai (1994) o sistema de melhoria deve passar por três estágios: primeiro estágio a administração colabora com os operadores a promoverem sugestões sem considerar o quão simples elas sejam, mas que reflitam no melhoramento das atividades e da área de trabalho; no segundo estágio, a administração deve promover o treinamento dos associados de maneira que os operários ofereçam melhores ideias e sejam capazes de analisar melhor o ambiente de trabalho e os problemas; e, por último, uma organização passa para o terceiro estágio, quando os operadores se mostram interessados e capazes de calcular o impacto econômico de suas ideia. 
A organização do estudo de caso, apesar de uma longa jornada dedicando-se aos programas de melhorias, encontra-se na transição entre o segundo estágio, que procura promover treinamento aos associados, de forma que esses tenham ferramentas disponíveis para analisar e propor melhorias a respeito de um problema, e o terceiro estágio, no qual os operadores se sentem interessados com o programa e buscam calcular o impacto econômico das suas melhorias.

Muitas melhorias sugeridas atualmente são pensadas de forma mais analítica pelos colaboradores da organização, pois eles vêm sendo capacitados de forma a pensar em ideias inteligentes para a melhoria dos processos. No entanto, alguns operadores se encontram em um estágio mais abaixo, propondo sugestões como identificações ou demarcações na área de trabalho. As figuras 5 e 6 representam dois exemplos de sugestões no estágio de baixa complexidade.

Figura 5 - Exemplo de kaizen no primeiro estágio do sistema de melhoria

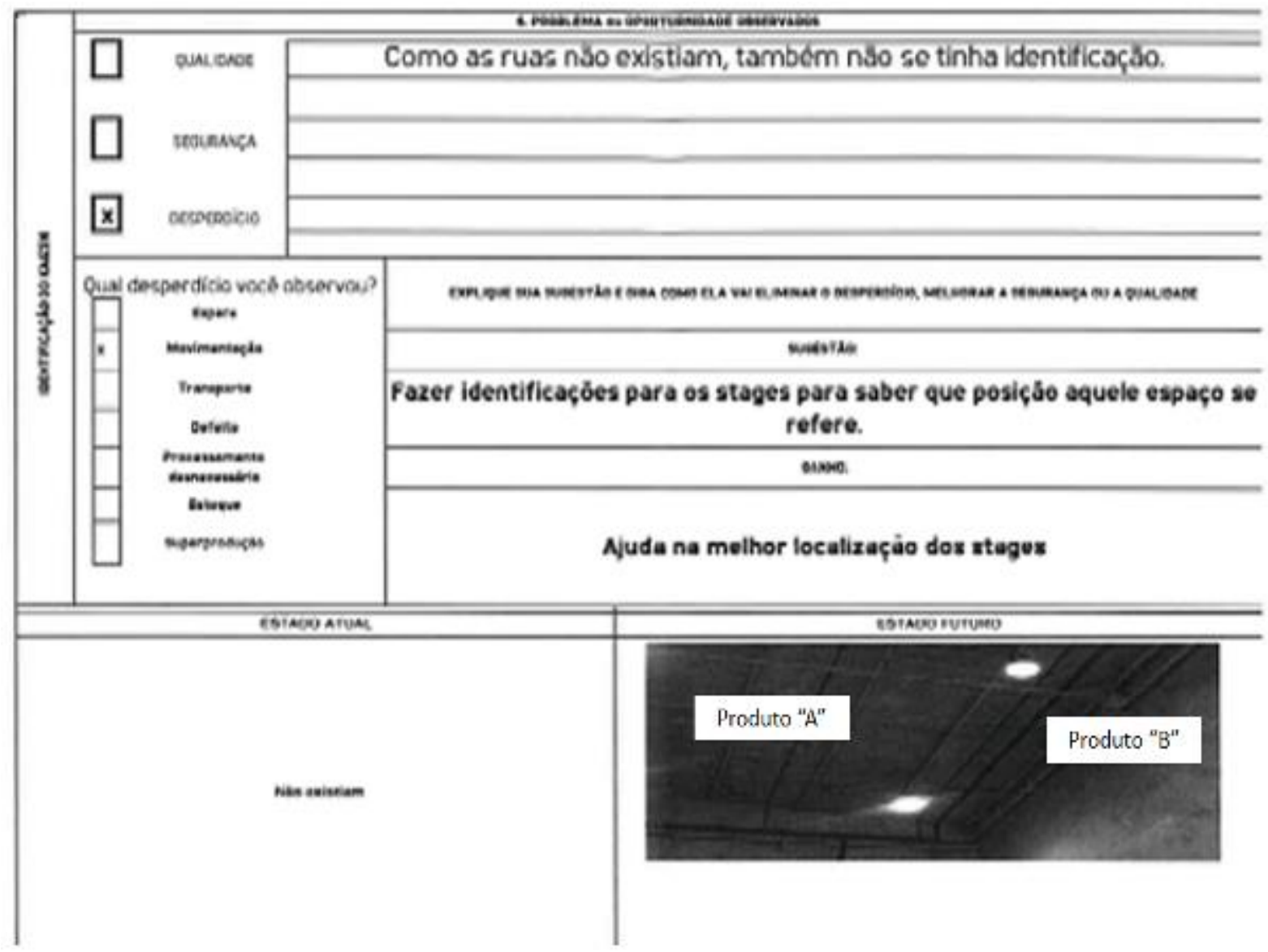

Fonte: Dados da organização (2019) 
Figura 6 - Exemplo de kaizen no Primeiro Estágio do Sistema de Melhoria

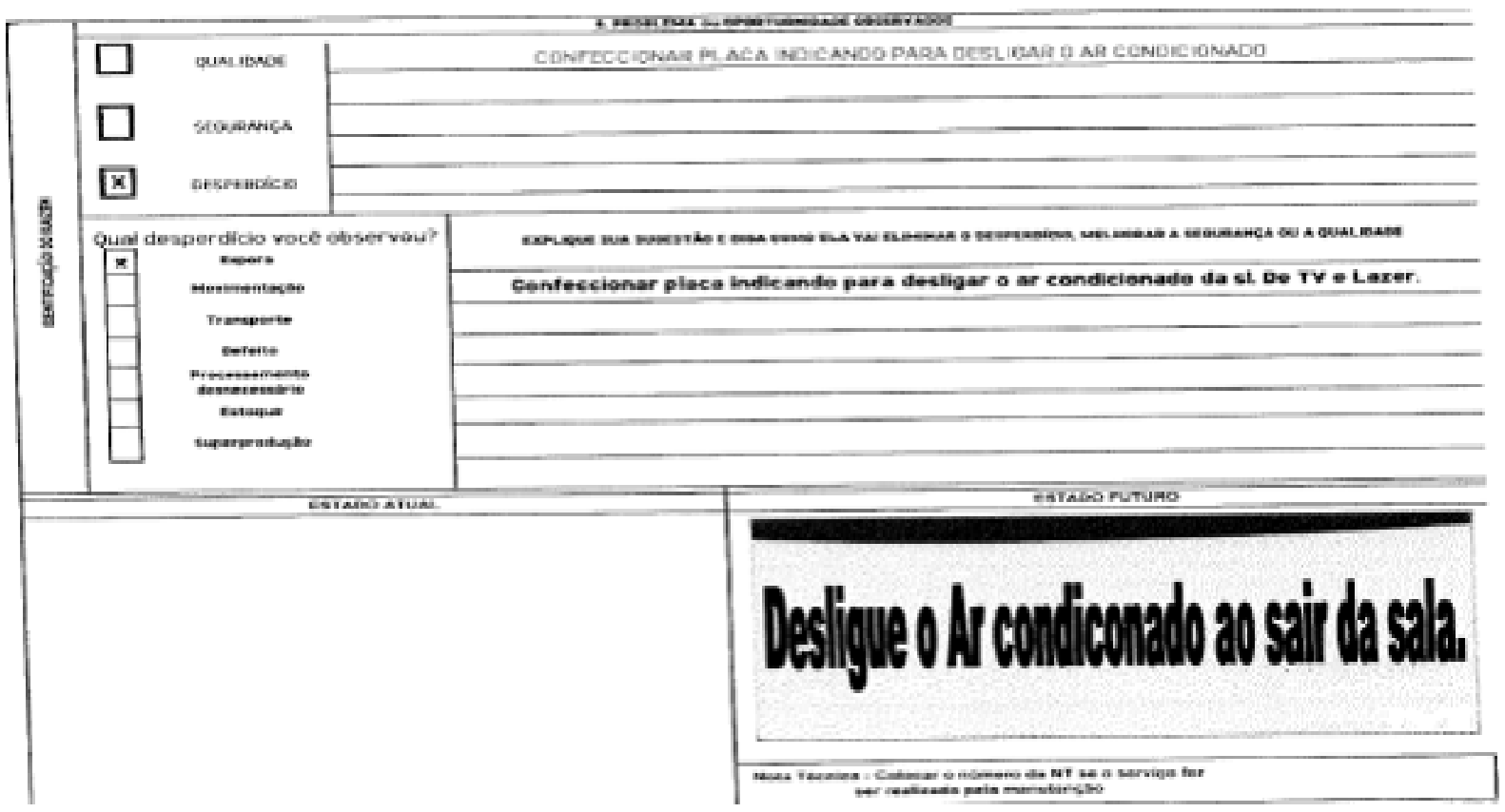

Fonte: Dados da organização (2019)

\subsection{Definição dos 7 desperdícios}

Outro tópico que merece discussão diz respeito à compreensão dos associados em relação aos conceitos dos sete desperdícios apresentados pelo modelo do Sistema Toyota de Produção. A proposta abaixo (figura 7) ilustra um equívoco de classificação.

Figura 7 - Classificação equivocada do desperdício

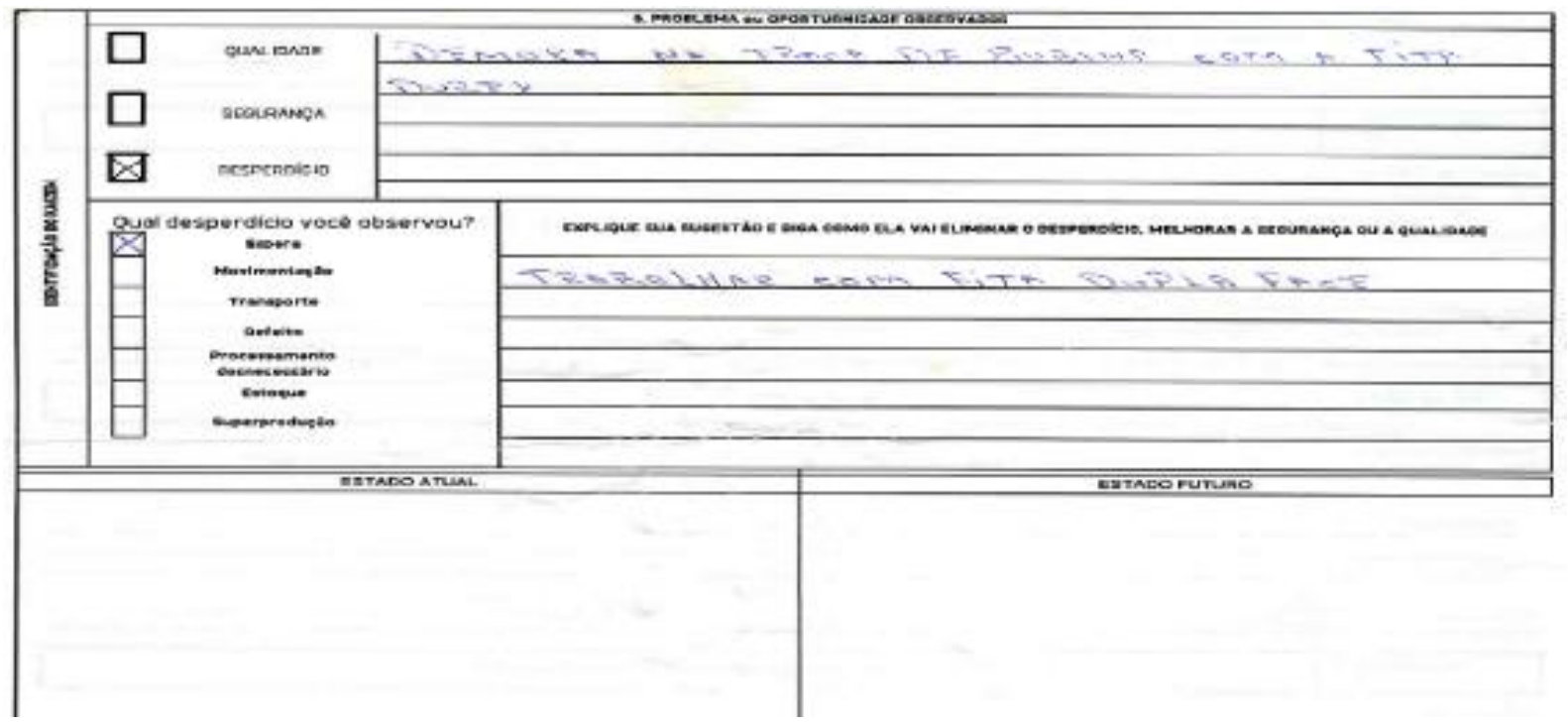

Fonte: Dados da organização (2019) 
Acima o operador sugere o uso de fita dupla face no lugar de fita durex. Com o uso da fita duplex evitaria de o operador dobrar a fita além de ser mais fácil para aplicar na bobina de embalagem. Sendo incialmente classificado como "espera", dado que esta melhoria evitaria uma movimentação do operador na operação de troca de filme da máquina de embaladora e eliminaria uma atividade desnecessária (dobrar a fita), esse desperdício seria melhor classificado como "movimentação" e "processamento desnecessário", pois com a sugestão de melhoria o operador deixaria de fazer a movimentação de "dobrar a fita" e com isso reduziria o tempo da troca do filme.

Acredita-se que a correta classificação da melhoria ajuda o associado a perceber como a sugestão melhora a sua atividade e seu ambiente de trabalho. Além disso, a cultura da melhoria contínua vai além de apenas sugerir melhorias por si só, trata-se de um programa para o desenvolvimento de habilidades dos empregados, ao aprender a avaliar uma situação a partir de vários ângulos (JHRA, 1992).

\subsection{Clareza em relação ao problema e descrição da proposta de melhoria}

A forma como um problema ou oportunidade identificado é descrito no formulário aumenta ou diminui a sua chance de ser implementado. Antes das melhorias serem realizadas, elas passam por um fluxo de aprovação, no qual serão avaliadas pelo líder direto do operador e os responsáveis dos departamentos de qualidade, segurança e manutenção. Caso as propostas não estejam bem descritas, o responsável reprova a sua implementação ou retorna para o associado para reformulá-la.

A seguir estão ilustrados alguns exemplos de sugestões mal desenvolvidas tanto em relação falta de detalhamento da melhoria (figura 8) e a identificação e descrição da problemática desacertada (figura 9). 
Figura 8 - Falta de detalhamento na descrição da melhoria sugerida

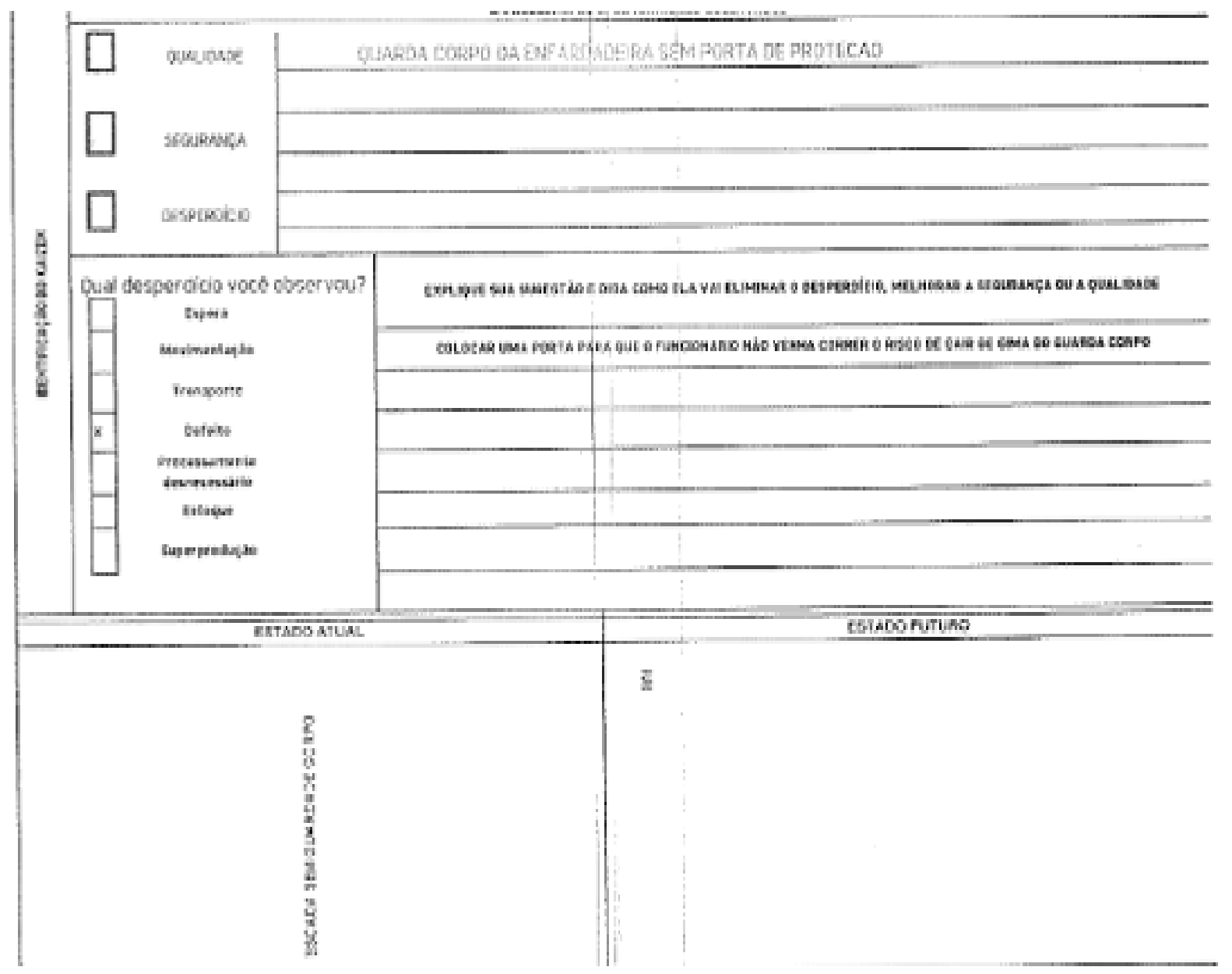

Fonte: Dados da organização (2019)

Na figura 8, para quem não é familiar com a operação, compreender do que se trata a proposta se torna um desafio. Dessa forma, recomenda-se uma maior participação do líder direto junto com o associado, em um primeiro momento, para melhor detalhar a proposta de melhoria. Além disso, verificou que como os associados têm uma meta de sugestões a propor, os mesmos submetem o formulário sem um olhar crítico apenas para cumprimento da meta, ou seja, isso reflete na falta de motivação dos associados para com o programa. Logo, ressalta para a importância de um acompanhamento da liderança, mostrando-se estar disponível e aberta para compreender e ajudar junto aos associados as melhorias dos processos sugeridas. 
Figura 9 - Exemplo de análise desacertada do problema/oportunidade observado

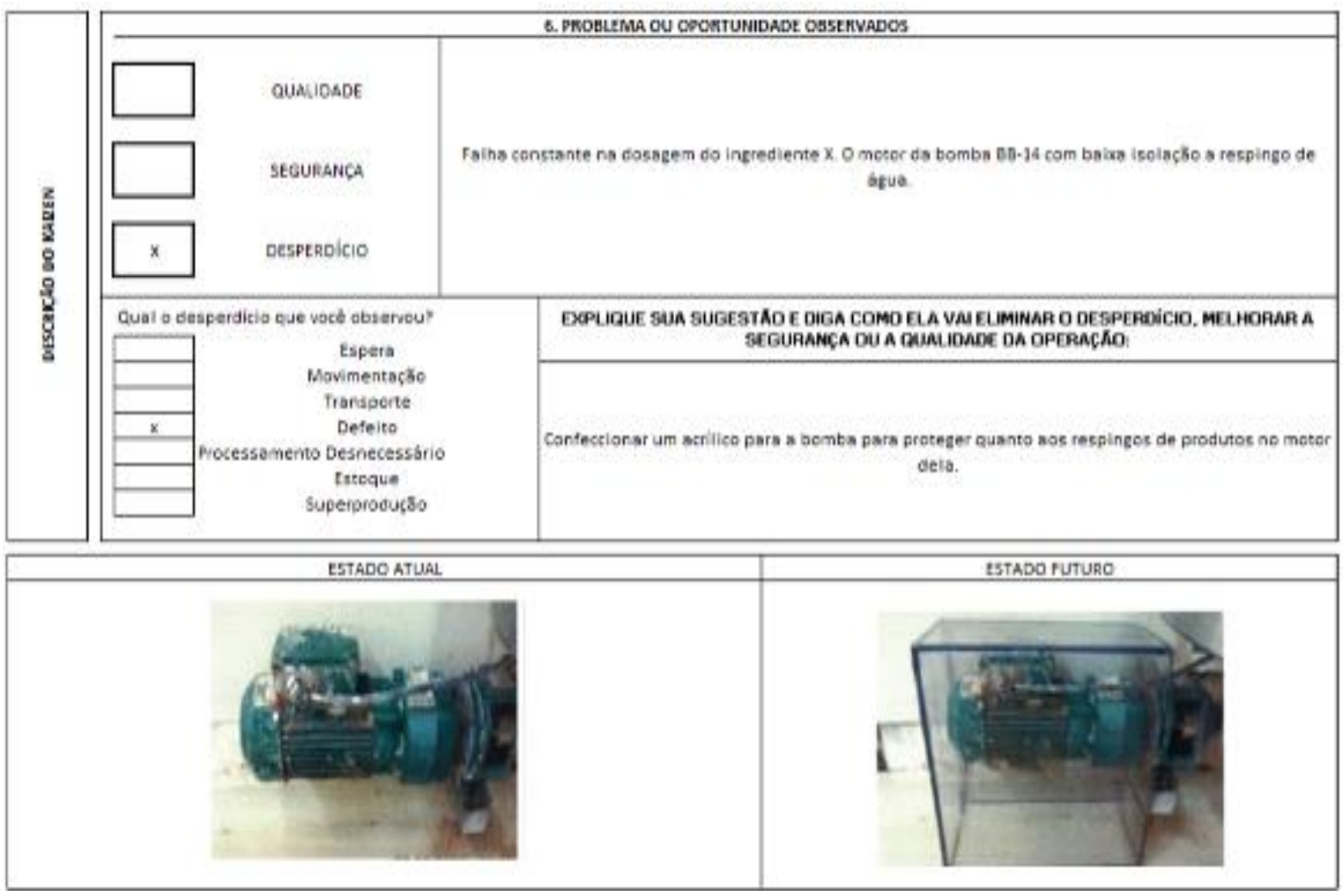

Fonte: Dados da organização (2019)

Na proposta acima (figura 9), ao propor confeccionar um acrílico para conter que a água não caia sob o motor da bomba, o operador apenas está julgando a consequência de um problema, que provavelmente não é "a bomba parada". Assim, propõe treinar os associados em ferramentas que os ajudem na investigação do problema e sua causa raiz, como por exemplo o 5 por quês ou $5 \mathrm{~W} 2 \mathrm{H}$, a fim de que as avaliações e os resultados sejam mais consistentes.

Além disso, a aproximação da liderança à operação com o papel de instruir também poderia ser uma oportunidade para desenvolver propostas congruentes às necessidades do processo e/ou pessoas envolvidas nele. Propõe-se investir na base teórica do kaizen, pois foca-se muito na implementação e negligencia na base teórica do programa.

\section{Limitações}

A maior dificuldade desse trabalho foi a escolha dos kaizen para ilustrar os exemplos ao descritos ao decorrer longo do trabalho. Haja vista o grande banco de dados disponível, mais de um kaizen se enquadrava no exemplo, buscou escolher uma sugestão que não requeresse 
um conhecimento técnico e aprofundado sobre o processo da organização e pudesse ser aplicado e quaisquer outras organizações.

\section{Conclusão}

Uma boa comunicação entre a alta gerência e os colaboradores, uma estratégia coorporativa clara, a presença de um Champion, gestão do conhecimento e empoderamento dos colaboradores podem ajudar na implementação do kaizen (MAAROF E MAHMUD, 2016).

Dessa forma, considera-se a importância do treinamento dos operadores para melhor descreverem suas sugestões, pois, apesar de todos conhecerem os conceitos de melhoria contínua, revelam uma deficiência em expor suas propostas no papel. Também, investir na capacitação dos aprovadores e responsáveis pela condução do programa de melhoria. Deve-se considerar que os kaizen não é um meio de cobrança por manutenção ou benefícios individuais no ambiente de trabalho, trata-se de estabelecer um acordo entre as partes, no qual todos os envolvidos saem ganhando com a melhoria. Criar uma base teórica sobre o kaizen ajuda no desenvolvimento de novos conhecimentos e habilidades para os envolvidos na organização, ajudando-os a pensar de forma diferente.

Além disso, a administração pode determinar semanalmente um período de atendimento junto aos operadores, a fim de discutir com eles as ideias propostas, mostrando-as sob uma perspectiva diferente, visitar o local de trabalho para compreender as propostas e ajudar no cálculo do retorno operacional e financeiro. Nesses encontros, o operador e o líder podem perceber oportunidades para melhorar a sugestão de kaizen inicial, o que garante criar um ambiente favorável de colaboração e aprendizagem entre a liderança e o liderado e estimular a contínua participação dos associados.

Existirão muitos desafios ao longo do desdobramento da aplicação da ferramenta, por requerer um esforço contínuo e acompanhamento diário sobre as ações e seus resultados, no entanto é mais fácil de se manter firme quando se tem clareza a respeito das vantagens dos programas para a organização, quanto a execução mais eficiente das atividades pelos indivíduos, melhor padronização da rotina de trabalho, redução de refugos de produção, resultando em processos mais enxutos e contínuos. Em razão disso, cabe a organização declarar seu compromisso para com todos da organização. 


\section{REFERÊNCIAS}

ALAGIĆ, I. Kaizen in Practice-Case Study of Application of Lean Six Sigma Method in Working Condition of Wood-Processing Firm. In: INTERNATIONAL CONFERENCE "NEW TECHNOLOGIES, DEVELOPMENT AND APPLICATIONS”. 2019, Saravejo. Switzerland: Springer, 2019. p 189-198.

BELIVEAU, P; GRIFFIN, A.; SOMERMEYER, S. The PDMA TOOLBOOK for New Product Development. Estados Unidos: WILEY. 2002. 480 p.

CARNERUD, D.; JACA, C.; BÄCKSTRÖM, I. Kaizen and continuous improvement - trends and patterns over 30 years. The TQM Journal. v. 30(4). p. 371-390. 2018

GERHARDT, T. E.; SILVEIRA, D. T. Métodos de pesquisa. Porto Alegre: Editora da UFRGS, 2009.

GIL, A. C. Como Elaborar Projetos de Pesquisa. São Paulo: Atlas. 4ª Edição. 2002.

GOŁAŚ, H. ET AL. Application of the suggestion system in the improvement of the production process and product quality control. IOP CONF. SERIES: MATERIALS SCIENCE AND ENGINEERING, 2016. DOI: https://doi.org/10.1088/1757-899X/145/6/062005

IMAI, M. Kaizen - A Estratégia para o Sucesso Competitivo. São Paulo: IMAM. Traduzido pelo Instituto IMAM. 5 Edição. 1994.

JAPAN HUMAN RELATION ASSOCIATION (JHRA). Kaizen Teian 2: Developing Systems for Continuous Improvement through Employee Suggestions. Estados Unidos: Productivity Press. 1997. 218 p.

KATO, I; SMALLEY, A. Toyota Kaizen Methods - Six steps to improve. New York: Taylor and Francis Group. 2011.

LIKER, J. The Toyota Way: 14 Management Principles from the World's Greatest Manufacturer. Estados Unidos: McGraw-Hill Education. $1^{\text {a }}$ Edição. 2004.

MAAROF, M. G.; MAHMUD, F. A Review of Contributing Factors and Challenges in Implementing Kaizen in Small and Medium Enterprises. Procedia Economics and Finance. v. 35.p. 522 - 531. 2016

MARTIN, K; OSTERLING, M. The Kaizen Event Planner: Achieving Rapid Improvement in Office, Service and Technical Environments. Estados Unidos: Productivity Press. 2007. 240p.

MAZZOCATO, P. Kaizen practice in healthcare: a qualitative analysis of hospital employees' suggestions for improvement. BMJOpen. 2016. DOI:10.1136/bmjopen-2016-012256

MOICA, S; VERES, C; MARIAN, L Effects of Suggestion System on Continuous Improvement: A Case Study. IEEE INTERNATIONAL CONFERENCE ON INDUSTRIAL ENGINEERING AND ENGINEERING MANAGEMENT, 2018, Tailândia. IEEE, 2018. p. 592-596.

OAKLAND, J. Gerenciamento da qualidade total. ed. 1. São Paulo: Nobel, 1994.

OLIVEIRA, M. F. Metodologia científica: um manual para a realização de pesquisas em Administração. Catalão: UFG. 2011

OLIVEROS, B. A.; GRANJA, A. D.; DIONISIO, S. R. An initial evaluation of a method for adopting kaizen events in the construction sector. Rev. ing. constr. [online]. v.33(2). p.173-182. 2018.

VO, B. et al.Kaizen event approach: a case study in the packaging industry International Journal Of

Productivity And Performance Management. v. 68 (7). p. 1343-1372. 2019. 